\title{
A Survey on Enterprise Resources Planning System for Enhancing Decision Making in the Egyptian Petroleum Sector
}

\author{
O.E. Emam \\ Department of Information Systems, \\ Faculty of Computers and Artificial \\ Intelligence, \\ Helwan University, P.O.Box 11795,
} Egypt

\author{
Shaimaa Mohammed Abdel \\ Hamid Auf, PhD \\ Department of information system \\ Faculty of Commerce \& Business \\ Administration, Helwan University
}

\author{
Mahmoud Mohamed Hassan \\ Department of Business Information \\ Systems, \\ Faculty of Commerce and Business \\ Administration, \\ Helwan University
}

\begin{abstract}
Enterprise Resource Planning system is one of the most important IT developments, it consists of integrated subsystems used to integrate and improve business management Functions Thus the Operational and Transactional aspects were the main reasons behind adopting ERP systems in companies, rather than capabilities of ERP on Supporting Decision, The Most studies on ERP systems were also aimed to evaluate their impacts on operational Aspects without adequate investigation on the relationship between ERP systems and decision support capabilities.

This Paper Discusses a research model for further investigate the relationship between ERP systems and Enhancing Decision-Making Process in the Egyptian Petroleum sector that has an important and vital role in the economic growth of Egypt.
\end{abstract}

\section{General Terms}

Decision Service, Petroleum Sector, integration, Data Mining Implementation.

\section{Keywords}

ERP, Decision making, Information technology, Cloud ERP Mobility ERP, Business intelligence

\section{INTRODUCTION}

Nowadays, Huge and volatile markets and technical progress have an immense impact on business environments in most organizations, as a result, companies, and organizations have to handle growing and huge volumes of data which have become an important and valuable asset, benefit from this asset has become essential for business success, through fast storage reliable data access, intelligent information retrieval.

Many difficult and complex circumstances lead to a widening circle of decisions to be taken, Managers in order to get prepared for making effective decisions are increasingly in need of various reports, analysis, and direct communication with relevant information, this led to considering information systems as a supportive framework for the integration of information with the decision-maker. ERP system is enterprise wide information system designed to coordinate all the information resources, and activities needed to complete business functions, once configuring it allows Data to enter at a single point in the process, and also updates Common Database for all functions that depend on this Data, thus ERP Systems were seen as the principal infrastructure of information systems that help to organize and transmit information relevant to decision-making, so ERP Systems have become an important instrument the Most enterprises could no longer function without it.

The Petroleum sector is one of the most important economic entities in Egypt, so this sector is always in urgent need of the availability of reliable and relevant information to make the right decisions in suitable time and in critical conditions accordingly appeared the need for expanding the use of information technology within the companies of the Egyptian petroleum sector through the establishment of a unified system for the management of petroleum sector resources and assets (ERP) for Enhancing Decision Making and Facing crisis, But Sometimes implementation of an Enterprise Resource Planning system does not justify the expectations of an enterprise, so organizations have to study and analyze carefully before implementing ERP Systems and to know the benefits of the implementation, Because Successfully implementation of enterprise resource planning systems creates organizational synergy which support decision making process, Therefore this paper Discusses the impacts of ERP system on the Egyptian Petroleum Sector and how it can be used to Enhance the efficiency Decision Making of this Vital sector.

\section{LITERATURE REVIEW}

Most Previous studies of ERP systems were aimed to evaluate their impacts on improving transactional and operational processes, without taking into consideration their importance and impacts in the decision-making process, this study hypothesizes a research model for further investigation in the importance and influence of ERP on the decision-making process.

The search Conducted by using more than 20 scientific search engines, and after examining more than 100 articles, 40 of them were selected, categorized, and then synthesized, to provide useful information about how ERP systems contribute to improving the decision-making process.

\subsection{ERP Implementation in The Oil and}

\section{Gas Sector}

in the study by Jafari, A. A., \& Nair, S. S. K. (2018, August). found that Resource planning is an important component of the organization's strategy, effective management of resources is critical for companies operating in a turbulent environment such as the oil and gas industry, so the study aimed to study the efficiency of an ERP system to deal with resources and identify the constraints and challenges during Implementation in the oil and gas sector in the Sultanate of Oman and Exploring how ERP effects on the efficiency, the productivity 
of this important sector, the study indicated that the oil and gas sector should implement an ERP system to enhance its growth in all aspects [1].

in the study by Barman, H. (2017). The study investigated that the ERP system is an important driver for business success and the productivity of the enterprise, and this study considered that no systematic study has been conducted to measure the productivity of the enterprise in the refineries due to the implementation of ERP, and measuring the productivity of the enterprise is not an easy process, so this paper researched In feedback from ERP users in Assam refineries in India for developing an enterprise productivity measurement framework that can be used in Indian refineries.

The study found that KPIs are important to ensure that the ERP project can give business results on expected lines and that they can be measured, which is why organizations use KPIs during and after implementing ERP, Measurement frameworks are a way to structure KPIs around an organization's strategy, goals and objectives.

The study has proven that the key thing about a benchmarking framework is that it can be understood and helps the organization understand the relationship between KPIs as well as the KPIs themselves, Data, in general, is not a problem but the real problem is getting the correct data for the correct measurement, A robust enterprise measurement framework is a key requirement for analyzing and improving the productivity of an existing organization.

This study can be used as a basis for developing similar measurement frameworks in other countries in the refining sector as well as in other sectors [2].

Implementing ERP systems especially in companies operating in a turbulent environment such as the oil and gas industry may facing many critical challenges during the implementation. In the study by Menon, S. A. (2016). This exploratory single-case study investigated critical challenges encountered during the implementation of ERP based on individual perspectives in four project roles: senior leaders, project managers, project team members, and business users, all specifically in the oil industry and Canadian gas. The study had shown the correct conditions for implementing ERP systems, emphasized the importance of benefits and process improvements in ERP implementation, and found that there are critical challenges facing the implementation of ERP which are significant during the implementation of ERP, the study made ten key recommendations on how to improve ERP applications in the future [3].

\subsection{ERP Systems Adoption for Improving Decision-Making Process}

According to OUIDDAD, A.et al., 2018, In the past decades ERP systems have grown and evolved greatly, and they have become of great importance for the analysis of operational data thus, there is direct communication between ERP systems and decision-making in the enterprise. this article aims to analyze past research work on the role of ERP in improving decision making and provide useful information about the contribution of ERP systems on improving the decision-making aspects of the organization. the results of this study focused on highlighting the relative lack of studies on the role of ERP systems in decision-making and referred that more quantitative studies should be done to understand better how ERP systems positively affect decision-making [4].
The study conducted by Holsapple, C., Sena, M., \& Wagner, W. (2019) has aimed to explore the links between ERP systems and decision support based on the perceptions of 53 people adopting the ERP system. This study provided new insights into the important relationship between the perceived success of ERP system, and its role as a basis for implementing more advanced decision-making support, and focused on how users perceive the success of their ERP system in relation to some key features of integrated decision support systems, as such links have so far received little attention in either the enterprise system or the DSS literature, because Enterprise system literature only focuses on the record-keeping and transaction processing functions of enterprise software, with minimal emphasis on decision support aspects [5].

The study conducted by Pekša, J., \& Grabis, J. (2018) reviewed the decision-making capabilities of ERP systems and identified the different approaches for integrating decision-making logic into ERP systems, this review leads to an initial integration framework, which assesses current solutions used in the integration. Paper noted that separating decision-making logic from enterprise resource planning (ERP) systems enables the use of advanced decision-making techniques for decision intensive business processes in realtime despite the need to improve the logical integration between business processes and decision-making components [6].

According to OUIDDAD, A.et al., 2020, An enterprise resource planning (ERP) system have become commonly used for automating operational processes and enhancing their efficiency inside a company, the increasing and continuous development of ERP technologies has increased their impacts on decision-making. The purpose of this study was to investigate and evaluate the effects of ERP systems on improving the quality of decision-making in large Moroccan companies. The results of the investigation showed that the information and the quality of the system had a positive effect on the overall user experience with the ERP system, while the quality of service had a negative effect on it, which affected the quality of decision-making [7].

Kumar, A. (2018). Stress that real-time information is one of the major challenges in the markets, especially in vital industries such as the pharmaceutical industry where information is one of the main concerns. So, this paper aimed to present the ERP system and indicated its impact on the commercial decision-making process in a pharmaceutical company, and this was done through a literature review using secondary data from various pharmaceutical company's case studies, ERP implementation diagrams, books, journals, and research papers in the field.

The results indicated that ERP system as a business solution can help pharmaceutical companies integrate their business processes across the enterprise, thus helping to avoid data redundancy, ensuring data reliability, accuracy, and in real time, while reducing opportunities for inconsistency, and lower costs by Increase flexibility, support faster and corrective decision-making [8].

According to Nađ, J., \& Vražić, M. (2017, June).In the manufacturing environment, Decision making is a strategic topic, to have high efficient decision-making, the top managers must have a proper tool for tracking information related to the current and upcoming business events and 
opportunities, All available data should be collected in, "one place" and evaluated in a relatively easy and quick way, so decision-makers could have enough time for their main jobs, This paper aimed to describe and clarify the idea of using ERP software's in transformer manufacturers to improve the decision-making where it is possible to improve decisionmaking process in companies for the production of electrical machinery by including rough designing procedure in ERP systems, where it is possible by including technical calculations of approximate design procedures and transformer analytical model modeling in ERP systems, as SAP as an ERP software is a suitable tool for this idea [9] .

In the study conducted by Santo, W. (2016). To present the impact of ERP systems for supporting decision making using dashboard system to enhance the performance of organizations. the study found that the implementation of ERP systems can improve the efficiency and productivity of work, ERP systems can help The Managerial levels to take strategic decisions easily through the use of dashboard systems, the ERP systems links using dashboard systems help the managers of the organizations to generate the best decisions accurately in any time, any place, to increase the flexibility that supports management, ERP systems using dashboard systems have become a critical issue for organizations that provide integration that supports core business processes increase the efficiency of Decision-Making Process [10]

Hadi, A. A. et al., 2018. Stress that although previous studies discussed the critical success factors for failure or success of the ERP system and the extent to which it achieves the desired goals, focused The current study on the significant impact of the social, technical, and decision-making environment on the success of the ERP system, in addition to the lack of research on ERP as a mediator in the above-mentioned relationship, This explanatory study aimed to define the mediating role of ERP in the relationship between the impact of the socio-technical approach, the decision-making environment, and the sustainable performance of companies, this study stimulated to bridge the literature gap. The study showed found that ERP is an important mediator between the link between the social and technical elements and the decision-making environment while the organizational culture has a little moderate role in the relationship between the social and technical elements and the ERP systems [11].

\subsection{Implementation of Cloud and Mobility ERP Systems}

The cloud is especially important for small and medium-sized companies because it provides full access to functional applications at a reasonable price without large expenses on hardware and software by avoiding the initial costs for all computing infrastructure such as hardware and data servers and it reduces IT support services because IT support is provided By the data center, and Finally reduces the cost of maintaining and supporting these applications as the cloud vendor handles updates and upgrades.

in the study conducted by Alsharari, N. M. et al., 2020, The study investigated the implementation of a cloud enterprise resource planning (ERP) system and the main factors that users practice and challenges they may face, and it also presented a detailed comparison between cloud ERP and traditional ERP systems. The study provided evidence that using the Cloud EPR system, as an alternative to the traditional ERP system is an important issue for improving the quality of the decision making process and the success of organizations, the study also revealed that the effectiveness of
Cloud ERP implementation Depends on the professionalism of the provider; Which led to issues related to reduced organizational independence [12].

AlBar, A. M., \& Hoque, M. R. (2019). Stress that Cloud ERP systems are a very useful contribution to the field of information systems, as they provide: flexibility, cost reduction, scalability, adaptability, availability, and interchangeable data to any type of company, however, there is a dearth of research looking at the influencing factors On the adoption of cloud ERP, especially in developing Middle Eastern countries, the research was aimed to study the factors that affect the adoption of cloud ERP in the Kingdom of Saudi Arabia, and this study is an important addition to the literature in that it is one of the few studies discuss Factors that affecting cloud ERP.

The study provided practical guidance for the successful adoption of cloud ERP in the Kingdom of Saudi Arabia and assisting other developing countries in similar circumstances in planning and utilizing cloud ERP services. Governments organizations and policymakers will benefit from this study in overcoming challenges and effective adoption of ERP in the cloud [13].

Organizations realize that mobility solutions lead to more modern and accurate information, as information processing speed is increasing today, creating the need for accurate, real time data that is easily accessible from anywhere.

Mobile ERP is an ERP system that can be run and accessed through mobile devices, such as tablets and cell phones, where users usually using a standard browser or dedicated mobile applications to access the system via the Internet, so users are able to access their business remotely, which means that It is possible for employees and field service personnel to capture and enter data wherever they are.

According to Tai, Y. T. et al., 2020. In today's complex and competitive business environment, companies generally use Enterprise Resource Planning (ERP) systems to integrate management information and enhance efficiency, recently due to the development of cloud computing and mobile devices, a new era of mobility has begun. The popularity of tablet computers and smartphones has changed the behavior of mobile phone users and promoted the rapid development of mobile commerce, ERP companies have discovered this trend and want to provide more convenient services and develop more integrated functionality for their ERP systems where practitioners can work and access company information through many mobile devices anywhere, anytime. However mobile ERP is still in the stage of research and development there has been little research into the framework and implementation of a mobile ERP system until near time, this paper aimed to Provide a mobile ERP framework for the sales function of an ERP system, where authors designed a mobile type sales app based on an Android mobile device, and they provided sales practitioners and supervisors with a more convenient service interface and link through which they can quickly respond to customer needs. To demonstrate the efficiency of a mobile ERP system, the authors examined three scenarios commonly used in IC design firms, as sales reps travel to different cities and collect sales information. Results showed that a mobile ERP system enhances processing efficiency in sales and distribution units, especially for sales representatives who visit external offices and travel around the world [14]

\subsection{Integrating of ERP Systems with}




\section{Business Intelligence Tools}

Alguliyev, R. M.et al., 2016. state that in recent years economic and social activity fields are based on data, Oil, and gas industry leaders understand the value of big data and are interested in the digital oil industry becoming a reality, where Here is big data is analyzed as a key component in based decision making in oil and gas industry during exploration, drilling, and production. An architectural model is offered in the oil and gas industry for integration and convergence of big data, business analytics, and transaction data. The study concluded that the oil and gas industry sector is rapidly adapting to the information age and has entered a digital transformation. During this period, oil and gas companies that entered information with terabytes and sometimes petabytes per day need new analytical tools to get ideas in collecting and interpreting data accurately to predict potential and maintain costs at Minimum etc. With regard to data analysis, the main issue is the integration of data received from different sources and in various forms (structured and unstructured), and the proposed integration architecture can be applied in the fields of oil and gas industry such as exploration drilling, processing and so on [15].

Rouhani, S., \& Mehri, M. (2016). discussed the benefits of implementing ERP on business intelligence (BI) readiness. The research showed many positive relationships between the benefits of implementing ERP and business intelligence readiness criteria, such as, improved interaction with customers, improving decision-making, increasing flexibility in information generation, Integrated information across the enterprise and, and Improving information flow between departments, as the benefits of ERP implementation lead to the business intelligence readiness of the enterprise.

This research will be useful for corporate CIOs to prepare their organizations to use Business Intelligence through ERP implementation, plus the insights on ERP impacts and its relationship to the level of business intelligence are the key findings of the current research [16].

Koupaei, M. N.et al (2016). conducted a unified framework for the application of business intelligence in ERP systems, where the business process system and the interaction between technology and the environment through the application of business intelligence in ERP systems for companies that use flexible manufacturing systems were introduced, According to this paper, it is important to answer this question "How can use data and potential intelligence for business intelligence in ERP systems for effective flexible manufacturing systems?", This study contains four hypotheses to answer this question and based on the results, all four hypotheses have been confirmed [17].

Elango, D., \& Thiagarajan, V. (2016). Focused on the advantages of integrating ERP with business intelligence tools for making wise decisions by business enterprise executives.

This paper showed that Different functional departments have used ERP to obtain supportive information and decision making at the functional level, as the integrated business intelligence tools with the ERP Package provide the decision making process at the strategic level and vision-based visualization, executives may take the organization has a future-oriented decision from legacy information processed in the business intelligence tool with ERP.

This paper Concludes that BI tools can be used in various types of ERP packages and also used in many MIS programs regardless of industry sectors such as small, medium, and large enterprises [18].

Caserio, C., \& Trucco, S. (2018). focused on analyzing the role that ERP, BI, and the combined adoption of ERP and BI systems in reducing or managing information overload / under load, and thus in improving the quality of information perceived by Italian managers, moreover, analyzing the impacts of information flow on the perceived quality of information. The results showed that the co-accreditation of ERP and BI systems is more important for information overload/under load, and for information flow characteristics than single accreditation for ERP or BI systems and conclude that the information processing capacity has a positive effect on the information quality; Therefore, if the information processing capacity increases, the quality of the information perceived by the respondents also increases. Moreover, the results show that communication and reporting have a negative effect on the quality of the information perceived by the respondents, so that if communication and reporting increase the quality of the information decreases [19].

Ray, P., \& Kumar, T.A (2019). showed that although most large organizations are currently investing huge amounts of money and resources in order to implement ERP systems and business intelligence to face the competitive world that exists today, where ERP and business intelligence have become important and essential strategic tools that have a direct impact on the success and failure of any organization. There is however, a lack of interest in the proper integration of ERP and business intelligence. Therefore, this paper includes the implementation of ERP systems and business intelligence models, as well as other reporting and data simulation tools, to conduct a comparative case study aimed at assessing the important causes leading organizations to upgrade and implement ERP and business intelligence systems in relation to potential relationships Between them. The paper noted that ERP and BI work together to give managers the power required to make important decisions, through ERP capabilities to integrate all available data into a common database, and the advantages of new business intelligence tools, which play an important role in enhancing the quality of decision-making using data collected from systems Enterprise resource planning. Business intelligence improves the ERP system because it efficiently collects data, stores and analyzes it, and gives it access to data to help users make better organizational decisions. However, an effective business intelligence approach must pay close attention to the data structure, because ultimately, they are the root of most decision support systems. Business intelligence integration with ERP helped organizations integrate all technologies and provide direct access to the system from anywhere.

People from different departments in the organization need a set of ways to use the information, and they need analysis tools that are easy to learn and use, and business intelligence makes sure that network-related information flows freely through the organization, providing employees with a means through which they can communicate and collaborate, so companies are now moving on Broad scope towards implementing business intelligence in ERP due to the accessibility and data cleansing techniques that are properly implemented with this integration [20].

\section{RESEARCH METHODOLOGY}

For Assess the impact of the ERP system in the Egyptian petroleum sector and how this system affects the efficiency of decision-making in the Egyptian petroleum sector The Quantitative and qualitative research methodologies have 
been used. The literature review of the implementation of ERP systems has provided data regarding The Challenges and Critical factors for Successful ERP implementation and Impacts of ERP system on the efficiency of Decision-making in organizations and then walk through the latest technologies and Evolutions of the implementation of ERP such as cloudy ERP systems, mobility ERP, and the Integrating Between ERP and Business intelligence.

\subsection{Sampling and Data Collection}

\subsubsection{Sample composition}

A survey was conducted among 100 Persons of Senior information technology officials at the Ministry of Petroleum and the Egyptian General Petroleum Corporation and Four Major Petroleum Companies Which are included in The seventh axis of the Egyptian Petroleum Sector Development Program (the digitization of energy and support the decision making) which are Cooperation Petroleum Company (CPC) Petroleum Pipelines Company (PPC), Petroleum Gas Company (Petrogas), and Misr Petroleum Company (Misr). IT experts and Information technology managers in the Egyptian petroleum sector were included in this Sample. The Responses were recorded in electronic versions for Analyses.

\subsubsection{Primary data sources}

The main data source for this research is the questionnaire. To design the questionnaire and in order to support the information gained from the literature review on ERP implementation and its impact on the decision-making process, some interviews were conducted with senior officials and information technology experts at the Egyptian Ministry of Petroleum and Egyptian General Petroleum Corporation as well as some visits to Petroleum Companies were conducted. The visits and interviews helped develop a practical understanding of challenges and issues of the implementation of the ERP system and had given insight into various parameters that determine the impact of the ERP system on the efficiency of the decision-making process in the Petroleum Sector.

\subsubsection{Secondary data sources}

The secondary sources of data included the information Gained from journal articles, websites, and reviews of IT experts reviews Opinions of officials, Experts of the oil and gas industry in Egypt, and Reviews of academic studies about the influence of ERP system on the efficiency of Decisionmaking Process. The secondary data sources included also the information and reports from Information systems applied in some Petroleum Companies, to analyze and understanding the Expected impacts of the ERP system implementation on the Company performance and increasing Efficiency of the Decision-Making Process at the company, where the reports provided qualitative and quantitative data for the Research.

\section{ANALYSIS OF SURVEY FINDINGS}

The questionnaire designed for the survey of the impact of the ERP system on the efficiency of decision making in the Egyptian petroleum sector Includes fifteen questions, these questions investigate the extent of the compatibility of the ERP system with the Work Functions and systems in Egyptian Petroleum companies and How can ERP System enhance the efficiency of Decision-making Process in The Egyptian Petroleum Sector. The Responses from the participants were taken in the questionnaire in a form of affirmation or negation of the statement of the corresponding question, the questionnaire provided the Possibility to add the opinion other than the affirmation or negation of the statement.

The analysis of the data shows that approximately $72 \%$ of the respondents believe that it has become imperative that the petroleum sector benefits from technological progress because of its great impact on the Performance of the Egyptian petroleum sector, and they believe that the adoption of ERP System will have a lot of benefits for the Egyptian petroleum sector, They believe that ERP can remove all the defects of the old Information Systems applied in The petroleum companies and it will also have a tangible role in improving the efficiency of the decision-making process in petroleum sector companies through The integration and ease of Transfer and circulation of data and information across various administrative levels.

Others responded that the Adoption of the ERP system may be not beneficial for the Petroleum sector Because the implementation of it will complicate the Business Functions Performance and the existing systems of the oil and gas industries and it may be not able to support decision making in the petroleum Sector as Expected.

Most of the participants see that ERP is one of the information technology Technics that introduced a paradigm shift in the operations of many organizations and accelerated the operational efficiency and has facilitated the effective management of most activities in the organizations, Which made ERP System plays an important role in supporting decision-making process by facilitates Transfer and circulation of information relevant to the decisions to be taken, Thus the most of participants agree that Petroleum sector of must develop Databases and using shared Database for all business processes by implementing ERP to optimize the resource planning and increase the efficiency of making Decisions.

\section{CONCLUSION}

The analysis of research survey findings and Reviewing the literature showed that the Enterprise Resource Planning system is one of the important IT developments, where used to integrate and improve business processes for effective planning and enhancing the Decision making, therefore, the ERP system is based on standard business rules and provides a common database for all business Functions.

Because ERP systems are commonly used to automate operational processes and enhance their efficiency within the organization, so Most studies on ERP systems were aimed to evaluate their impacts on operational and transactional processes, without taking into consideration their importance and influence on supporting decision- Making. in recent years Enterprise Resource Planning (ERP) systems have significantly grown and evolved and with the wide development and application of real-time technologies and big data, the relationship between ERP systems and decisionmaking support has become more explicit.

Reviewing the literature showed that there are challenges critical factors for successful ERP implementation, that must be taken into consideration During the implementation and post-implementation and it also Showed the latest evolutions of the implementation of ERP such as cloudy ERP systems mobility ERP, and the Integrating Between ERP and Business Intelligence systems, it turned out that Cloud ERP systems are a very useful contribution to the field of information systems where transition to Cloud ERP could lead to various process benefits in the enterprise control system, reducing cost scalability, adaptability and availability, however, there is a 
dearth of research looking at the influencing factors on the adoption of cloud ERP, especially in developing Middle Eastern countries and it turned out that mobility solutions can lead to more recent and accurate information, where Mobile ERP users are able to access their business remotely and it is possible for employees and users to capture and enter data wherever they are, so transactions on mobile applications can be more efficient because the user does not need to import and export data from ERP to the mobile application, so data can be presented in real-time, as the data is communicated between Real-time ERP and mobile applications, however there is a shortage of researching about the implementation of The Mobile ERP Systems.

Reviewing the literature showed that co-accreditation of ERP and BI systems is very important for improving the quality of information, and for information flow characteristics than single accreditation for ERP or BI systems, where ERP and BI work together to give managers the power required to make important decisions, through ERP capabilities to integrate all available data into a common database, and the advantages of new business intelligence tools, which play an important role in enhancing the quality of decision-making using data collected from systems Enterprise resource planning. Business intelligence improves the ERP system because it efficiently collects data, stores and analyzes it, and gives it access to data to help users make better and fast decisions, although most large organizations are currently investing huge amounts of money and resources in order to implement ERP and business intelligence to face the competitive world that exists today where ERP and business intelligence have become important and essential strategic tools that have a direct impact on the success and failure of any organization, There is, however, a lack of interest in the integration between ERP and business intelligence.

Through analysis of research survey findings and reviewing past research works on the role of ERP in improving decision making useful information about the Expected contribution of ERP systems for improving the decision-making aspects of the Egyptian Petroleum Sector were provided. The relative lack of studies on the role of ERP in supporting decisionmaking was also highlighted.

\section{REFERENCES}

[1] Jafari, A. A., \& Nair, S. S. K. (2018, August). ERP Implementation in the Oil and Gas Sector: A Case Study in Sultanate of Oman. In 2018 7th International Conference on Reliability, Infocom Technologies and Optimization (Trends and Future Directions) (ICRITO) (pp. 848-854). IEEE.

[2] Barman, H. (2017). Enterprise Productivity Measurement Framework for ERP in Indian Refineries.

[3] Menon, S. A. (2016). Critical challenges in ERP implementation: A qualitative case study in the Canadian oil and gas industry (Doctoral dissertation, Capella University).

[4] OUIDDAD, A., Chafik, O. K. A. R., CHROQUI, R., \& HASSANI, I. B. (2018, November). Does the adoption of ERP systems help improving decision-making? A systematic literature review. In 2018 IEEE International Conference on Technology Management, Operations and Decisions (ICTMOD) (pp. 61-66). IEEE.

[5] Holsapple, C., Sena, M., \& Wagner, W. (2019). The perceived success of ERP systems for decision support. Information Technology and
Management, 20(1), 1-7.

[6] Pekša, J., \& Grabis, J. (2018). Integration of DecisionMaking Components in ERP Systems.

[7] OUIDDAD, A., Chafik, O. K. A. R., CHROQUI, R., \& HASSANI, I. B. (2020, April). Assessing the impact of enterprise resource planning on decision-making quality.in https://www.emerald.com/insight.

[8] Kumar, A. (2018). The Impact of ERP Systems on Business Decision-Making in Pharmaceutical Company. ZENITH International Journal of Business Economics \& Management Research, 8(4), 58-63.

[9] Nađ, J., \& Vražić, M. (2017, June). Decision making in transformer manufacturing companies with help of ERP business software. In 2017 15th International Conference on Electrical Machines, Drives and Power Systems (ELMA) (pp. 379-382). IEEE

[10] Santo, W. (2016). Enhancing Performance of an ERP Systems with a Dashboard Systems. In International conference on information management and technology (p. 5).

[11] Hadi, A. A., Alnoor, A., \& Abdullah, H. O. (2018). Socio-technical approach, decision-making environment, and sustainable performance: Role of ERP systems. Interdisciplinary Journal of Information, Knowledge, and Management, 13, 397-415.

[12] Alsharari, N. M., Al-Shboul, M., \& Alteneiji, S. (2020). Implementation of cloud ERP in the SME: evidence from UAE. Journal of Small Business and Enterprise Development.

[13] AlBar, A. M., \& Hoque, M. R. (2019). Factors affecting cloud ERP adoption in Saudi Arabia: An empirical study. Information Development, 35(1), 150-164.

[14] Tai, Y. T., Huang, C. H., \& Chuang, S. C. (2016). The construction of a mobile business application system for ERP. Kybernetes.

[15] Alguliyev, R. M., Aliguliyev, R. M., \& Hajirahimova, M. S. (2016, October). Big data integration architectural concepts for oil and gas industry. In 2016 IEEE 10th International Conference on Application of Information and Communication Technologies (AICT) (pp. 1-5). IEEE.

[16] Rouhani, S., \& Mehri, M. (2016). Does ERP have benefits on the business intelligence readiness? An empirical study. International Journal of Information Systems and Change Management, 8(2), 81-105.

[17] Koupaei, M. N., Mohammadi, M., \& Naderi, B. (2016). An Integrated Enterprise Resources Planning (ERP) Framework for Flexible Manufacturing Systems Using Business Intelligence (BI) Tools. International Journal of Supply and Operations Management, 3(1), 1112

[18] Elango, D., \& Thiagarajan, V. (2016). Advantages of Integrating ERP with Business Intelligence Tools. Research Journal of Science and IT Management, 5(5).

[19] Caserio, C., \& Trucco, S. (2018). Enterprise Resource Planning and Business Intelligence Systems for Information Quality. Springer, Rome.

[20] Ray, P., \& Kumar, T. A. (2019). ANALYSING THE INTERFACE OF BUSINESS INTELLIGENCE AND ENTERPRISE RESOURCE PLANNING. 